\title{
Los puentes y la Comisión de Arquitectura (1786-1808)
}

\author{
José EnRique García Melero
}

La creación por la real orden del 22 de marzo de 1786, la puesta en funcionamiento en la primera junta del 21 de abril y la actividad posterior de la Comisión de Arquitectura causó cierto optimismo en un principio en la Academia. Se pensaba que esta Bella Arte había conseguido grandes avances con ello, acercándose a los ideales del clasicismo gracias a la legislación promulgada por el Rey a petición de los académicos desde el año 1777 y al gran quehacer del nuevo servicio.

Pero, además, el número de los proyectos censurados aumentó mucho desde la fundación de esta Comisión. Se logró una mayor fluidez a la hora de despachar burocráticamente los expedientes por la intervención del Vicesecretario y la convocatoria de las juntas con un carácter al principio quincenal durante todo el año 1786 y más tarde mensual. El Secretario general también se descargó de un trabajo considerable, así como las juntas ordinarias de la Academia, en las cuales ahora ya tan sólo se tenían que aprobar corporativamente los dictámenes de las de la Comisión; es decir, sin tener que realizar el estudio y la censura de los proyectos en cada una de sus reuniones, inmiscuyendo en tal labor a los profesores de las diferentes artes. Este organismo se especializaba, así, en una parcela concreta de las Bellas Artes.

Antonio Ponz justificó en el resumen de las Actas -leído en la junta pública del 14 de julio de 1787 convocada con motivo de la distribución trienal de los premios de la Academia- la creación de la Comisión debido a la enorme actividad burocrática generada por esta labor censoria, que resultaba excesiva para él y que ocasionaba un considerable retraso en el despacho de los expedientes. Tal quehacer desmesurado le había obligado a quejarse ante el Rey en 1786, porque, además, no le dejaba tiempo suficiente para dedicarse a redactar su «Viaje de España». Carlos III le desocupó de esta labor decretando la constitución 
de ese servicio para que pudiera ocuparse de los principales asuntos de su empleo '.

El Secretario cuantificó brevemente en dicho resumen de las actas, iniciado con la notificación de una Real Cédula del 1 de mayo de 1785 promulgada por el Rey sobre la libertad de las Bellas Artes, la labor censoria realizada por la Academia entre 1785 y 1787 . Se había examinado el considerable número de ciento cuarenta expedientes y casi otros tantos dibujos para obras públicas, habiéndose propuesto también arquitectos para el reconocimiento de ellas. Sin embargo, aunque esta cantidad ya era bastante importante en estas fechas, aumentaría rápidamente en volumen con el transcurso de los años, tal y como se verá más adelante, para estacionarse su crecimiento hacia 1792.

Pero el optimismo académico sobre los últimos avances logrados en la Arquitectura se puede apreciar sobre todo al leer el resumen de las actas siguientes, expuesto el 4 de agosto de 1790 con motivo, asimismo, de la distribución de los premios concedidos por el Rey. Ponz escribió en tal ocasión que «el público puede ya ser buen testigo de los adelantamientos que se van haciendo, por lo que ha visto en los tres últimos en edificios considerables y decoraciones, tanto en la Corte, como en otras partes" '

Según Ponz todo ello era la consecuencia de que las ordenes del Rey, para que no se hicieran obras de consideración sin que sus proyectos fuesen estudiados y aprobados por la Academia, se hubieran observado mucho más durante el período comprendido entre los años 1787 y 1790 . También opinaba que este logro se debía a que por fin se habian visto en el Reino las ventajas de tal actividad académica. De esta forma no se habian malgastado los caudales en "caprichos y extravagancias", invirtiéndose, por el contrario, en "obras dignas», que acreditaban «su recto modo de pensar en lo venidero».

Tal hecho justificó todo el optimismo del Secretario de la Academia. Pensaba que la Arquitectura se recuperaría en el futuro del estado deplorable, en que se hallaba. Este logro se manifestaría especialmente en la decoración arquitectónica. Pero, además, era posible alcanzar un fin pedagógico, pues las obras «indecentes», que quedasen, serían conocidas y

\footnotetext{
"Distribución de los Premios concedidos por el Rey Nuestro Señor á los discípulos de las Nobles Artes, hecha por la Real Academia de San Fernando en la junta pública de 14 de julio de 1787. Madrid, En la Imprenta de la Viuda de lbarra, Hijos y Compañía, 1787. Véase págs. 5-6.

2 «Distribución de los Premios concedidos por el Rey Nuestro Señor á los discípulos de las Nobles Artes, hecha por la Real Academia de San Fernando en la junta pública de 4 de agosto de 1790\%. Madrid, en la imprenta de la Viuda de Ibarra, 1790. Véase págs. 7-9.
} 
despreciadas en todas partes, y se corregirían aquéllas que se pudieran enmendar. Todo lo cual le hizo afirmar: «Llegará por fin antes de mucho esta importante arte a un grado, que nadie hubiera creído pocos años ha; y volviendo al camino real, y verdadero con que la introdujeron y propagaron en el siglo diez y seis los Toledos, Herreras, Gómez, Covarrubias, Vergaras y Bustamantes, y otros que siguieron sus pisadas, tomará nuevo incremento. Cuanto se fabrique será regular, y entre lo bueno habrá cosas superiores para crédito y honor de la nación".

Ese mismo optimismo se puso asimismo de manifiesto en el poema, escrito por el presbítero José Ortiz y Sanz, entonces académico honorario, titulado "Mercurio convida a Manzanares a ver las obras premiadas, $y$ demás del concurso". La composición, aunque en verdad sea literariamente poco agraciada, tiene el mérito de haber sido escrita por el autor de la traducción "De Architectura» de Vitruvio, publicada significativamente en 1787, un año después de crearse la Comisión de Arquitectura. En la segunda estancia aludía a los avances logrados en la censura de obras públicas, escribiendo lo siguiente:

«Hoy bastará que veas la destreza, la aplicación, esfuerzos y conatos con que esos candidatos de esta Deidad penetran los secretos.

Mira la gallardía y gentileza del módulo Corintio: los ornatos Matronales del jónico, tan gratos a Diana Efesina: los preceptos Dóricos tan fundados y discretos.

Todo se va atendiendo, y todo corrigiendo:

Todo rectificando:

Todo se va reviendo y mejorando.

La época pues espera, en que reviva desta Arte la grandeza primitiva» ${ }^{3}$.

Si en el trienio anterior no se cuantificaron los expedientes y proyectos censurados por la Comisión, en el resumen de las actas de la Academia del 4 de agosto de 1790 hasta el 20 de agosto de 1793, realizado con motivo de la distribución de los premios en la junta pública reunida en esta fecha, se aportan nuevos datos bien minuciosos y elocuentes. Durante esos años se habían despachado mil treinta y dos negocios de inspección; se pasaron

3 Ibidem, págs. 106-110. 
a informe 251 expedientes de toda clase de edificios, habiéndose visto 731 planos o diseños de obras y evacuado 30 informes solicitados por varios tribunales de dentro y fuera de la Corte sobre diferentes puntos artísticos. Por último, se nombraron en veinte ocasiones arquitectos para la formación de planos de obras públicas, pedidos por el Consejo y las partes interesadas en dichas obras ${ }^{4}$.

\section{LAS TIPOLOGÍAS DE LAS OBRAS PÚBLICAS EN LA COMISIÓN}

Diversas tipologías de obras públicas pasaron por las juntas de la Comisión de Arquitectura. Muchas de ellas no pueden ser consideradas como específicamente arquitectónicas al ser analizadas desde nuestra perspectiva actual, sino construcciones totalmente ingenieriles. $Y$ aún en aquella época debieron contribuir a fomentar la separación entre un cuerpo de arquitectos y otro de ingenieros civiles al cercionarse políticamente de su misma especificidad técnica y del distinto tratamiento que habia que dar a unas obras con relación a otras. Pero en esta época comenzó a distinguirse entre los campos específicos del Arte y de la Técnica, que hasta entonces no se habían diferenciado totalmente, confundiéndose. No es extraño, así pues, que en 1802 se creara la Escuela de Ingeniería Civil. Ya entonces tal labor de la Comisión debía extrañar a más de un político por la diversidad de tipos de construcciones que en ella se analizaban, pues antes de su creación ya se distinguía entre las obras públicas ingenieriles, objeto de la censura encomendada a Marcos de Vierna, y las arquitectónicas, de las que Ventura Rodríguez se había ocupado, tal y como el Consejo de Castilla lo tenía establecido con anterioridad a la carta circular de 1777.

La mayoría de estas obras censuradas eran, asi pues, puentes, carreteras, canalización de aguas... No suele haber en tal labor proyectos de edificios realmente importantes por su carácter representativo, obras que, por lo general, casi siempre corrían a cargo del patronazgo regio y cuyos proyectos no eran enviados a la Academia. El Reino estaba atravesando en estos momentos por una época de inicio de una grave crisis económi-

\footnotetext{
"Distribución de los premios concedidos por el Rey Nuestro Señor a los discípulos de las Tres Nobles Artes hecha por la Real Academia de San Fernando en la junta pública de 20 de agosto de 1793". Madrid, en la Imprenta de la Viuda de lbarra, 1793. Véase pág. 12. Estos datos fueron notificados en un oficio por Luis Paret, como Vicesecretario, fechado el 27 de agosto y hechos ya públicos en la junta ordinaria del 8 de septiembre de 1793. A.A.S.F.: 3/85, fol. 264 rev. Oficios de Paret y Bosarte, y relación de obras censuradas por tipologías arquitectónicas en A.A.S.F.: leg.: 28-1/5.
} 
ca, por lo cual se prescindió de todo, o casi de todo, lo innecesario. Hay en el fondo en esta labor de la Comisión un contexto siempre económico: era preciso acabar con los gastos supérfluos en la construcción. El clasicismo ofrecía de esta forma cierta garantía como tendencia artística desornamentada, que no empleaba más decoración que la estrictamente necesaria. $Y$ el ornato excesivo exige siempre mucho dinero. Existe, por lo tanto, el afán de eliminar los costes prescindibles en los dictámenes de estas juntas de arquitectos académicos, abaratamiento que fomentaban, además, los Consejos de las villas, los fiscales del Consejo y Cámara, y los mismos escribanos de gobierno.

La crisis económica del Reino con el alza de los precios y de los salarios - que se manifestó desde 1793 al declarar la convención francesa la guerra a España, acentuándose en 1796, año de iniciación de la lucha contra Inglaterra- es totalmente perceptible a través del estudio cuantitativo, y hasta del cualitativo, de estas censuras. Hay de una forma clara un descenso importante en el número de diseños y de expedientes que llegaron a la Academia para su estudio entre 1786 y 1808 , después de un momento de auge con su límite hacia 1793. Desde entonces se llevaron a cabo las obras realmente importantes por su grado de necesidad, por su utilitarismo, viejo ideal de la llustración. Por ello, y a pesar de esa crisis, se siguieron realizando con Carlos IV, o se trató de cumplir, un viejo programa ilustrado de mejoras iniciadas ya durante el reinado de Fernando VI e impulsadas plenamente con Carlos III.

Hay, además, una diferencia clara en el número de obras censuradas entre las pertenecientes a la arquitectura civil y a la religiosa, que fueron bastante menos numerosas. ¿Se estaba secularizando ya la sociedad como consecuencia de las ideas revolucionarias francesas, dándose más importancia a las construcciones para la vivencia del hombre sobre la tierra que a las realizadas con la finalidad de que alcanzara el cielo? ¿Escapaban más fácilmente en este momento a tal labor censoria las realizaciones arquitectónicas eclesiásticas que las civiles? ¿Disponía el Estado de más medios que la Iglesia? Todos y cada uno de estos aspectos en particular debieron incidir de alguna forma en la supremacía de la arquitectura civil sobre la religiosa. Pero lo manifiesto es que en esta época de finales de la llustración la política constructiva se dirigía, pragmáticamente, mucho más hacia el progreso económico, social y cultural del hombre, produciéndose un momento de vitalismo, que propició una práctica constructiva muy utilitaria.

Tales claras diferencias cuantitativas existentes entre las obras civiles y eclesiásticas ya se percibe con toda evidencia en el mismo 1786, año fundacional de la Comisión de Arquitectura. Así, de entre los 79 asuntos des- 
pachados en las catorce juntas celebradas desde el 21 de abril, que tuvo lugar la inicial, al 21 de diciembre, 59 de ellos se relacionaban con las primeras y tan sólo 20 con las segundas. Este número representa proporcional y respectivamente el $74,68 \%$ y el $25,31 \%$ del total.

Los puentes fueron las construcciones civiles que más trabajo dieron a los arquitectos de la Academia. Los 23 expedientes por encima de los proyectos religiosos, significan el $29 \%$ de la totalidad y el $38 \%$ de las obras seculares. Las sigue la tipología carcelera, cuyo edificio solía estar unido al de las casas consistoriales, con 12, que da lugar a una proporción del $15,18 \%$ de ese total y del $20,33 \%$ de las civiles. Otras construcciones civiles objeto de censura eran los caminos, los canales y conducción de aguas dulces, puerta principal, plaza de toros, pilar itinerante...

La realización de iglesias parroquiales y colegiatas ocupó el primer lugar dentro del capítulo de la arquitectura religiosa. Los 7 expedientes despachados representan el $8,86 \%$ de la totalidad y el $35 \%$ de las realizaciones eclesiásticas. Hay que destacar a su lado los 6 altares, las 3 torres y el campanario y los 2 trascoros, así como, finalmente, la caja de órgano y un facistol.

Es significativo que en este año de 1786 se construyeran más casas consistoriales y cárceles que iglesias parroquiales. El utilitarismo ilustrado y también la crisis económica propiciaron, sobre todo, la realización de arquitecturas necesarias y sencillas, más económicas, basadas en la estética clásica, de formas claras, funcionales y desornamentadas. La magnificencia festiva fue desplazada por la sobriedad pragmática en función de toda una ideología totalmente moderna. Interesaba, sobre todo, comunicar las distintas localidades entre sí para lograr su progreso, salvando montañas, valles, ríos y vaguadas... Desde esta perspectiva es bien manifiesto el progresismo de la política ilustrada, que parece alejarse algo del ideal religioso tanto como se preocupa por la mejora del nivel vital de los súbditos. Se abre el camino a la desacralización del arte de la centuria decimonónica.

Los porcentajes indicados en la cuantificación de los proyectos censurados en la Comisión de Arquitectura durante el año 1786 encuentra un cierto índice corrector al someter a un estudio estadístico las obras vistas durante el trienio comprendido entre el 1 de agosto de 1790 y el 30 de ese mismo mes de 1793 según el informe elaborado por Paret enviado a Bosarte. De los 251 expedientes vistos en este servicio 169 corresponden a la arquitectura civil y 82 a la religiosa. Se establece, así, una proporción respectiva de $67,33 \%$ y $32,66 \%$ frente al $74,68 \%$ y el $25,31 \%$ de 1786 .

No obstante a este valor correctivo medio aproximado a un $7 \%$, que, creo, no modifica substancialmente las conclusiones antes indicadas, sigue siendo perceptible la mayor atención que este servicio tuvo que 
prestar a los asuntos civiles. De ellos 98 corresponden a la censura de expedientes de puentes, puentecillos, presas y otras obras de agua, lo cual representa el $39,04 \%$ del total y el $57,98 \%$ de las civiles frente al $29 \%$ y $38 \%$ respectivamente de 1786 . Ellos acrecienta bastante el peso específico que la realización de puentes tuvo en España en estos años sobre el resto de las construcciones.

\section{CARRETERAS Y PUENTES}

Por consiguiente, en esta primera fase de la Comisión de Arquitectura muchos de los proyectos de obras públicas censuradas en sus juntas eran diseños para la realización de puentes. Aún no se había establecido una diferenciación clara y manifiesta entre las profesiones de arquitecto y de ingeniero. Esta actividad estaba entonces directamente vinculada con el Ejército, ocupándose de hacer construcciones militares como fortificaciones, arsenales, poblaciones, puertos...

Pero durante este mismo período comenzaba ya a vislumbrarse la imperiosa necesidad de distinguir entre las obras propiamente arquitectónicas y las ingenieriles. Era preciso, así pues, la creación de un cuerpo específico de ingenieros civiles, desvinculados tanto de la práctica arquitectónica tradicional como de la actividad propia de los militares y especializados en este tipo de construcciones. Ello se lograría algunos pocos años después, en 1802, al crearse la Escuela de Ingenieros de Caminos y Canales por inspiración de Agustín de Betancourt. Este ingeniero, y asimismo académico de la de San Fernando, había criticado desde 1785 la intromisión de algunos arquitectos en la realización de caminos. Les acusó de cometer muchos errores en la construcción de puentes debido a su total ignorancia en este género de obras al carecer de los principios de la hidráulica.

El deseo de que los profesionales de la construcción se especializaran en parcelas concretas también estaba presente en la Academia. De esta forma, el consiliario Pedro de Silva en sus "Reflexiones sobre los estudios de la Arquitectura" de 1792, proponía una especialización por ramos y en función de una enseñanza previa peculiar. Estableció tres tipos diferentes de arquitectos, que se podrían denominar hidráulicos, civiles y militares. Correspondía a aquellos la construcción de puentes, canales y obras hidráulicas ${ }^{5}$.

5 Pedro de SILVA: «Reflexiones sobre los estudios de arquitectura». Madrid, 6 de noviembre de 1792. A.A.S.F.: Leg.: 18-1/1. 
La llegada de Felipe $V$ a España y la entronización con él de la dinastía de los Borbones propició el arreglo de las comunicaciones del Reino con la referencia siempre puesta en Francia. Uno de los principales objetivos de la llustración era lograr la potenciación de la economía con el fomento de la agricultura y el comercio para conseguir la prosperidad de los vasallos. Ello no era posible, si antes no se mejoraba el sistema vial, lo cual permitiría el desarrollo del comercio al sacar a la agricultura y la ganadería de su aislamiento regional y relacionar las distintas provincias entre sí.

Desde 1749, año en el cual Fernando VI promulgó unas ordenanzas de caminos para los corregidores del Consejo de Castilla, aumentaron las disposiciones regias orientadas al arreglo y crecimiento de las carreteras españolas, cimentadas en las antiguas vías romanas y de la Mesta ${ }^{6}$. En 1759 Carlos III publicó un real decreto disponiendo hacer caminos rectos, que comunicaran las distintas provincias entre sí. Se subvencionarían con un impuesto sobre la sal, dos reales por fanega. Estas disposiciones se concretaron -después de un real decreto del 10 de junio de 1761 disponiendo el inicio de las obras de los caminos de Andalucía, Cataluña, Galicia y Valencia - en el Reglamento del 2 de diciembre de ese año, en el cual se nombraba a Esquilache, Secretario de Estado y Hacienda, Super-intendente de caminos. Tal política, que en un principio se realizó de una forma lenta y algo tímida, y sin grandes resultados prácticos, culminaría durante la Secretaría de Estado del Conde de Floridablanca entre 1777 y 1792.

El sistema vial se basó en el mismo programa político centralista de esta época. Todas las carreteras se encontraban radialmente en Madrid como lugar de residencia de la Corte, estando sobre todo cuidados los caminos que la unían con los Sitios Reales. Se abrieron las comunicaciones de la Meseta con la región cantábrica. En 1763 ya habia tenido lugar la apertura del camino de Reinosa que comunicaba con Santander y un año después se iniciaba el tramo entre Peña de Orduña y Pancorbo, que incidía en el comercio con Bilbao, acabándose en 1775.

Los trazados de las carreteras del Reino también fueron objeto de estudio y de censura en las Juntas de la Comisión de Arquitectura. Sus dictámenes tuvieron siempre informes finales muy dispares. Así, en la junta del 28 de julio de 1786 se estudiaron cuatro planos de caminos trazados

\footnotetext{
- Recuero, Antonio: "Los caminos. De la herradura a la rueda". "MOPU", Revista del Ministerio de Obras Públicas y Urbanismo. Madrid, julio-agosto de 1988, núm. 356, págs. 65-86.
} 
en las provincias Vascongadas remitidos por el Escribano del Gobierno Pedro Escolano. Tres de ellos habían sido realizados por Juan Bautista Orueta y afectaban principalmente a la provincia de Vizcaya. Eran diseños de las carreteras que unían a Bilbao con Pancorbo, Durango con la fábrica de Armas del Rey y los confines de Guipúzcoa, y a esta Villa con la primera. Fueron rechazados porque no seguían nunca la línea recta en sus trazados, aunque el terreno elegido era orográficamente suave, llano y abierto. Se aludía a que las direcciones eran incómodas y tortuosas, porque el camino no atravesaba algunas de las tierras particulares. La Comisión propuso que el académico Fernando González de Lara, residente en Burgos, fuera al Señoría de Vizcaya a reconocer los sitios por los que pasarían tales carreteras e informase sobre los mejores medios para el acierto. Sin embargo, pareció mejor el trazado del camino entre Durango y la raya de la provincia de Álava, hecho por Manuel de Echanove, aunque también adoleciera, a pesar de su rectitud, de algunos parajes con ángulos agudos y recodos sin causa aparente, que debía justificar a la Academia?

Este programa de mejoras en el trazado vial del Reino, incluía obviamente el arreglo y la construcción de cuantos puentes existían o fueran necesarios levantar de nueva planta en los distintos itinerarios para salvar ríos y desniveles del terreno. Desde las reales cédulas de 1777 los proyectos dedicados a esta tipología, en donde la arquitectura y la ingeniería se encontraban, requerían pasar por la censura de la Academia madrileña debido a su misma condición de obra pública. Se unían en este instituto las funciones distintas realizadas por Ventura Rodríguez y Marcos de Vierna, Comisario de Guerra, para el Consejo. Sin embargo, carreteras y puentes eran competencias de dos organismos político-administrativos diferentes: aquellas dependían de la Superintendencia de Caminos, mientras que el Consejo de Castilla se ocupaba de estos últimos. Ello dio lugar a que a veces se construyeran carreteras sin puentes y puentes sin carreteras ${ }^{8}$.

Pocos meses antes de la creación de la Comisión de Arquitectura la junta ordinaria del 5 de diciembre de 1784 tuvo que informar sobre una representación del Contador de propios fechada el 2 de octubre. En ella de orden del Consejo se notificaba a la Academia, que el Rey había resuelto,

\footnotetext{
7 Acta de la Junta de la Comisión de Arquitectura del 28 de julio de 1786. A.A.S.F.: 139/3, fol. 38 rev. -39 anv.

" Alzola y Minondo, Pablo: "Historia de las obras públicas en España". Prólogo de Antonio Bonet Correa. Madrid, Colegio de Ingenieros de Caminos, Canales y Puertos - Ediciones Turner, 1979. Véase pág. 318. Ed. original en Bilbao, Casa de Misericordia, 1899 con el título «Las Obras Públicas en España. Estudio Histórico.
} 
que este organismo dictara las provisiones necesarias, para que se nombraran a los sujetos, que propusieran las Academias de las tres Nobles Artes, para realizar los puentes de alguna importancia según los casos que ocurrieran. Esta disposición, aprobada por real orden y publicada por el Consejo el 21 de octubre, acordándose su cumplimiento, se debía a los abusos cometidos por los llamados profesores facultativos al extenderse y excederse en las regulaciones de los gastos de los puentes ${ }^{9}$.

Se pedía que la Academia redactara y enviase al Contador las reglas que debían establecerse en todo el Reino, tanto para la construcción de puentes como de las demás obras públicas de consideración. La junta decidió responder que estas normas ciertas y oportunas, que eran una parte muy esencial de este Arte, las daban los buenos autores de arquitectura, como, por ejemplo, Vitruvio, Serlio y Scamozzi. La Academia no tenía nada que añadir ni tampoco que dar para la construcción de obras de consideración. Se limitó a decir que, si el arquitecto, a quien se encargaba la obra, era bueno, debía conocer dichas reglas según las diversas circunstancias y acertaría dando una construcción sólida, al regularla según la diversa calidad de los terrenos, la rapidez de las aguas, su mayor aumento en las crecidas, la naturaleza de los materiales y otros cimientos físicos indispensables a los arquitectos de calidad. Si no lo era, si fuera ignorante y falto de principios, de los cuales había un número increíible, de nada valía darle reglas, de las que no podía hacer ningún buen uso, al ignorar una parte tan esencial de su arte. Jamás acertarían por más normas que se les diesen, ni podría esperarse un buen éxito de sus obras.

En la contestación de la Academia se aludía a la traducción completa en castellano "trabajada» por José Ortiz y Sanz, que saldría en breve, realizada a la vista de los monumentos antiguos de Roma mediante los auxilios que el rey le dio para ello. También se citaba la próxima publicación del segundo tomo de la arquitectura de Benito Bails con un «difuso» tratado de puentes y obras hidráulicas. Pero la propuesta ideal del puente clásico se proporciona a través de la mención del «Libro Tercero de Arquitectura", donde Serlio proporcionó una serie de modelos romanos como los de Santangelo, Puente Sixto, Pons Fabricius y el Pons Milvius. En esta respuesta también se alude a Scamozzi, cuyo tratado " $L$ 'ldea della Architettura universale" se imprimió en Venecia en 1615 y se reedi-

9 Libro de juntas particulares. 1774-1785. A.A.S.F.: 3/84. Junta ordinaria del 5 de diciembre de 1784. Actas firmadas por Antonio Ponz. Véase fol. 269 rev. - 721 anv. 
tó en 1687 y 1694, en edición esta última poseída por la Academia en su biblioteca ${ }^{10}$, como ya la de 1764 publicada en París por Jombert ${ }^{11}$.

Esta disposición daba a la Academia muchas más atribuciones al tener también que informar sobre nuevos tipos de obras de cierta importancia, además de los puentes. Aumentaba, así, considerablemente su capacidad y poder de control en todo el Reino; pero también se hacían bastante más pesadas sus cargas de trabajo. De aquí que su referencia sea obligada, pues contribuyó mucho a la creación de la Comisión de Arquitectura. En esta época Carlos III estaba realizando una importante labor ingenieril con la construcción y la mejora de numerosos caminos, puentes, canales y otras obras hidráulicas, que exigían el empleo de profesionales cualificados y también una gran inversión económica. Por este motivo siempre se mostraría preocupado por la forma más adecuada de ahorrar dinero e impedir abusos, así como por conseguir buenos arquitectos. Las obras de este tipo estudiadas por la Academia para su aprobación o reprobación fueron cuantiosas a partir de este año de 1784 .

La preocupación de los políticos ilustrados por la realización de los puentes de la forma más perfecta se manifestó ya en la segunda junta de la Comisión de Arquitectura del 4 de mayo de $1786^{12}$. En su transcurso se leyó un oficio, fechado el 21 de febrero, del Escribano de Cámara Juan Manuel de Reboles de orden del Consejo. Preguntaba a la Academia a quién conceptuaba como el maestro arquitecto con mayor pericia en la realización de obras de puentes y calzadas. Los miembros de la Comisión estudiaron detenidamente este asunto desde distintos puntos de vista. Se acordó responder que a la Academia «sólo le consta la pericia de sus individuos, que los tienen por abonados para ésta y las demás clases de obras, pues todas ellas son parte de la Arquitectura». Pero se añadió lo siguiente por si hubiera alguna duda: "Que se debe distinguir entre los Arquitectos, a quienes toca disponer y dirigir las obras, y los constructores de ellas, los cuales, con solo serlo, ni son capaces de disponer las fábricas, ni merecen por sola su práctica el nombre de Arquitectos". La respuesta terminaba indicando que este orga-

10 Scamozzl: "L'ldea delle Architettura universale di...". In Venetia, apresso Girolamo Albrizzi, 1694. B.A.S.F.: B-1623.

11 Scamozzi, Vincent: "Oeuvres d'Architecture» de Vincent Scamozzi, Architecte de la République de Venise. Nouvelle èdition revue \& corrigée exactement sur l'originale Italien. A París, chez Jombert, Libraire du Roi pour l'Artillerie \& le Génie, à la Image Notre Dame, 1764. B.A.S.F.: c-1079. En la parte segunda, libro octavo, capítulo XVI, se refiere a «algunos puentes maravillosos de piedra hechos por los antiguos y otros de los modernos".

${ }_{12}$ Libro de actas de la Comisión de Arquitectura. Acta de la junta del 4 de mayo de 1786. A.A.S.F.: $3 / 139$, fol. 35 rev. 
nismo no podía calificar a una persona determinada en «desdoro» de los demás individuos.

De las respuestas dadas por la Academia en 1784 y 1786 se puede deducir que este organismo consideraba el diseño de los puentes como una tipología específica de los profesionales de la Arquitectura salidos de la Academia. Se aprovechaba la ocasión para dejar bien claras las diferencias existentes entre los arquitectos, formados en sus aulas y examinados por dicho instituto de las Bellas Artes, y los maestros de obras practicantes gremiales. Se desdeñaba la sola práctica en favor de una concepción teórica, basada en el conocimiento de los tratados del clasicismo. Además, se codificaba la construcción de tales obras dentro del sistema arquitectónico clásico como cualquier otra clase de edificio suntuario, aludiéndose a los libros de Vitruvio, Serlio y Scamozzi, como los textos que mejor abordaban el tema de la construcción de los puentes.

En tales respuestas no se hacía referencia a ninguno de los tratados de arquitectura militar entonces vigentes entre los ingenieros del Ejército. Este cuerpo también se ocupaba de la edificación de esa tipología de obra pública, aunque lo hiciese casi siempre desde una perspectiva militar. Ya en 1768 se habia traducido al español el "Tratado de fortificación" del inglés Muller de la edición original a base de notas y comentarios. Miguel Sánchez Taramas, ingeniero ordinario y profesor de la Real Escuela Militar de Matemáticas de Barcelona, establecía en sus adiciones un parangón entre las construcciones militares inglesas y las realizadas durante aquellos años en España ${ }^{13}$.

No podían faltar obviamente largas alusiones a los puentes en este tratado. El ingeniero militar español reprodujo modelos nacionales de tales obras, que reflejan tres momentos históricos distintos dentro de una concepción clasicista: el romano con los de Martorell sobre el río Llobregat y de Alcántara sobre el Tajo; el renacentista del puente de Almaraz o de Alvalat sobre ese mismo cauce del año 1552 y los contemporáneos al autor de tales notas. De entre éstos destaca el grabado de Pauner de la copia del plano, perfil y elevación del Puente Real del Jarama de Aranjuez, construido en 1760 por Marcos de Viena. Este Comisario de Guerra había ejercido la censura de obras públicas para el Consejo de Castilla, tal y como Ventura Rodríguez había hecho de las

:3 Muller, J., "Tratado de Fortificación ó Arte de construir los Edificios Militares, y Civiles". Escrito en inglés por... Traducido al castellano, dividido en dos tomos, y aumentado con notas, adiciones, y 22 láminas finas sobre las 26, que ilustran el Original, por D. Miguel Sánchez Taramas... Barcelona, por Thomas Piferrer Impresor del Rey nuestro Señor, Plaza del Ángel, año 1769. 2 vol., lám. pleg., $21 \mathrm{~cm}$. 


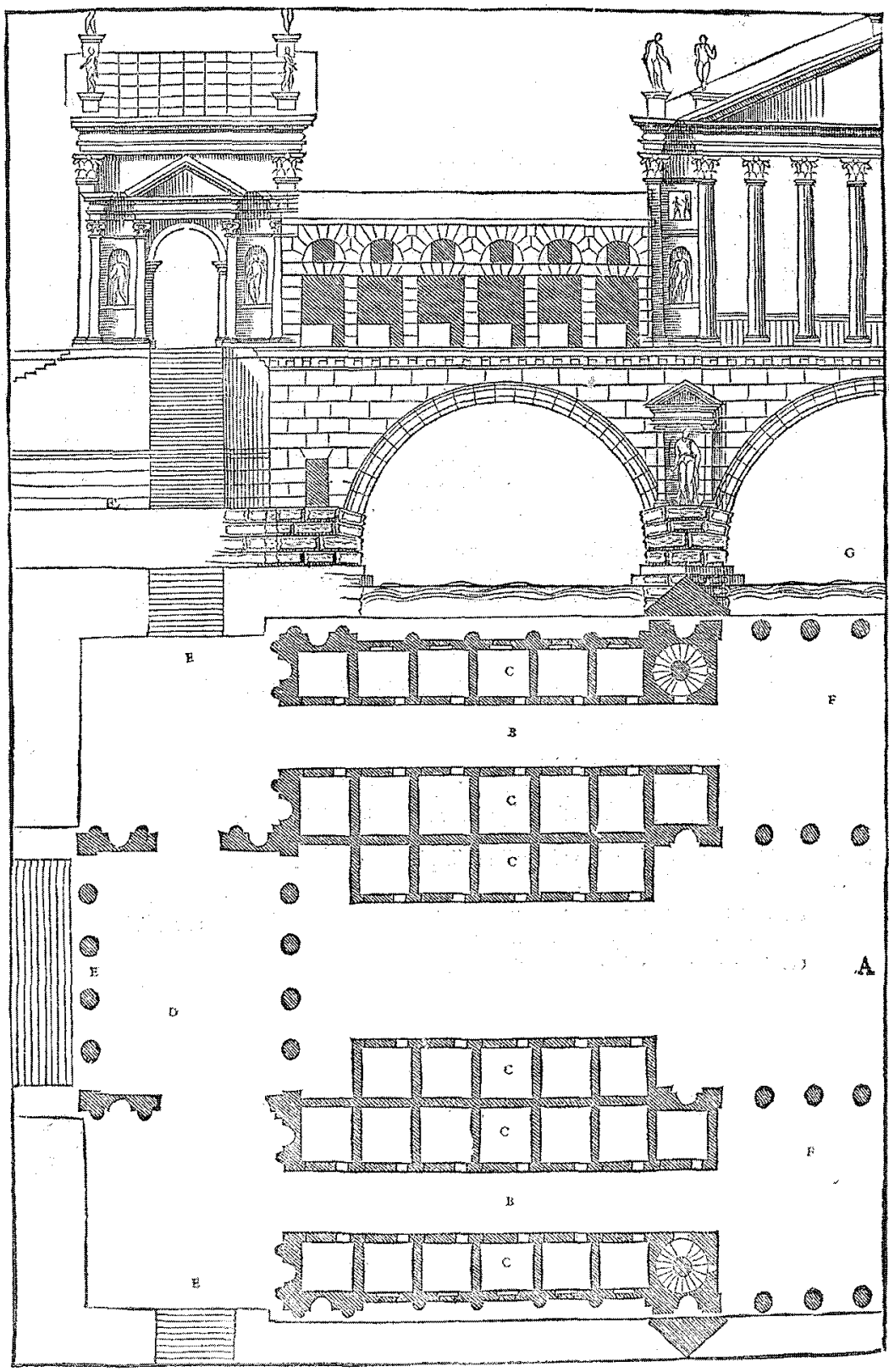

Fig. 1. Puente de piedra inventado por Andrea Palladio, en "I quattro libri delle'Architettura». In Venetia, Apresso Dominico de'Franceschi, 1570. Libro Terzo, p. 26. B.R.A.S.F.: B-1758. 


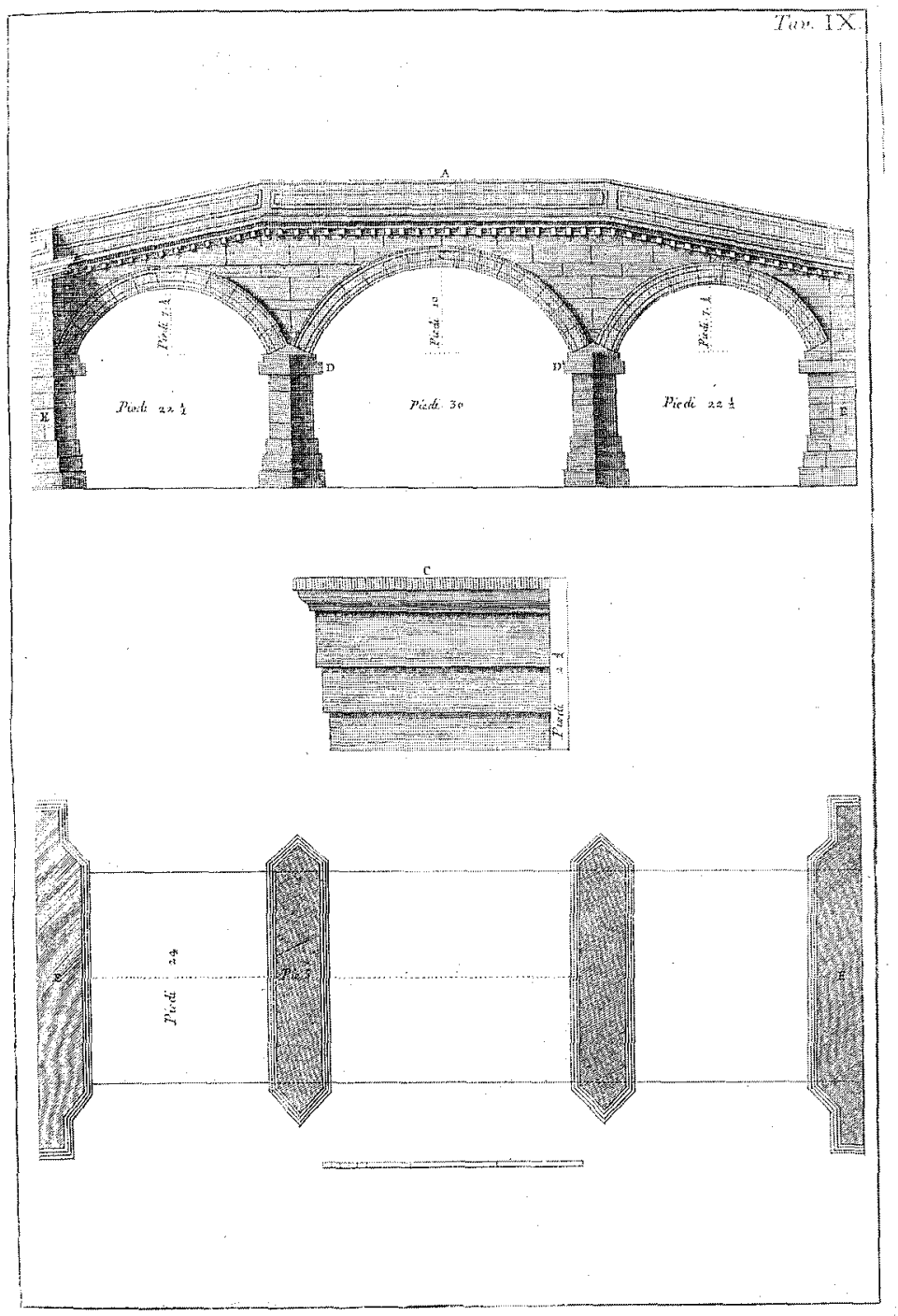

Fig. 2. Otro puente ideado por Andrea Palladio. «I quattro libri delle'Architettura". In Venetia, Apresso Dominico de'Franceschi, 1570. 
construcciones propiamente arquitectónicas antes de 1777. El nombre de Vierna aparecerá en varios de los dictámenes de puentes realizados en la Comisión de Arquitectura ${ }^{14}$.

En este libro se reproducían modelos de puentes según Palladio, tratado que era bien conocido en la Academia como demuestra la existencia en su biblioteca de las ediciones venecianas de 1570 y de 1748 , y de la parisina de 1764, además de la española de Ortiz y Sanz de 1797. No obstante, la última no fue operativa como modelo ni para el estudio de los discípulos de este centro ni en calidad de obra de consulta para su Comisión de Arquitectura, ya que publicó únicamente los dos primeros libros y tal tipología es tratada por el arquitecto vicentino en el tercero a lo largo de diez capítulos (del IV al xIII). Resulta extraño que en un período tan en la línea de recuperación de lo palladiano, durante el cual se censuraron tantos proyectos para esta clase de obra pública, no saliera a la luz ese tercer libro de una nueva traducción española ya iniciada, pues su empleo era oportuno y práctico entonces.

Es muy posible que el tratado de Palladio, tan directo como práctico y con escaso componente teórico, fuera estudiado, sobre todo, en la Academia por medio de la bella edición bilingüe, y por ello especialmente útil en la España de la época, en italiano y francés salida a la luz en Venecia por Ange Pasinelli de 1740, realizada por el arquitecto Giorgio Fossati ${ }^{15}$. En esta edición se imprimieron doce espléndidos grabados de puentes de madera y de piedra, ilustrativos del libro III, en el tercer volumen, tema que Palladio trata después de referirse a la construcción de los caminos y en parte como su complemento.

Pero en la Academia también se conserva la edición príncipe de Palladio, publicada en Venecia por Dominico Franceschi en 1570, que incorpora grabados xilográficos bellamente toscos, pero especialmente didácticos por su mismo esquematismo ${ }^{16}$. El arquitecto, siguiendo en mu-

14 GARcía MELero, J.E., «Los tratados de arquitectura militar publicados en España durante el reinado de Carlos III". En Espacio, Tiempo y Forma, serie VII, t. 3. Madrid, Facultad de Geografía e Historia de la U.N.E.D., 1990, págs. 181-224.

$\$ 5$ PALLADIO, Andrea: "Architecture de... de Vicence». Nouvellement mise au jour, corrigée, enrichie de planches en taille douce exactement dessinèes, enrichie de planches en taille douce exactement dessinèes, \&c. Augmentée de quantité de Bâtiments qui n'ont point puru jusqu'ici avec les remarques de l'Architecte n.n. Le tout traduit de l'italien. A Venise, chez Ange Pasinelli, 1740. 4 vols.. B.A.S.F.: B. 2836-39. Edición bilingüe italiana y francesa.

16 Palladio, Andrea: «l quattro libro dell'Architettura di Andrea Palladio». Ne'quali, dopo un breve trattato de'cinqui ordini, \& de quelli avertimenti, che sono piu necessarii nel fabricare; si tratta delle case private, delle Vie, de i Ponti, delle Piazze, de i xisti, et di'Tempii. In Venetia, Appreso Dominico di'Franceschi, 1570. A.A.S.F.: B-1758. 


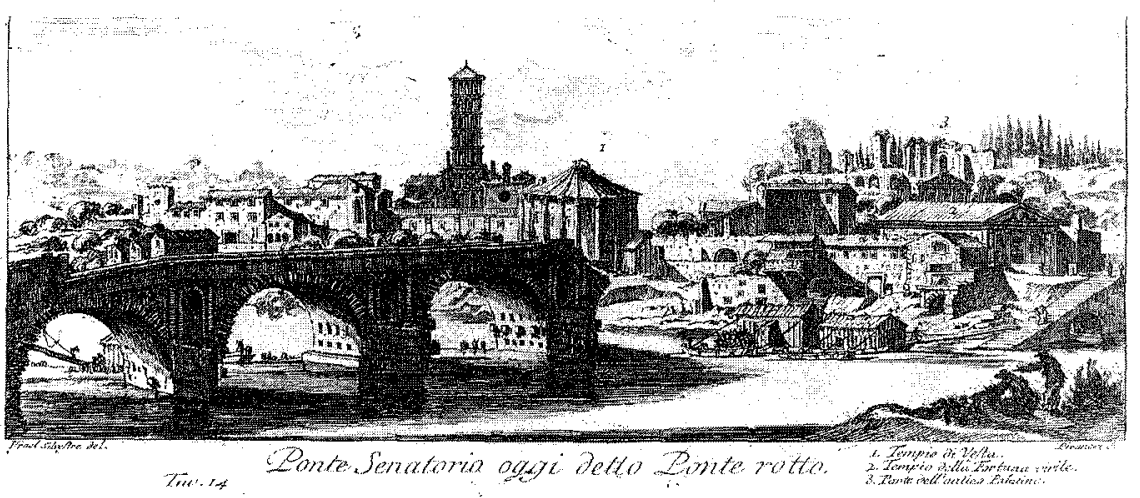

Fig. 3. Ponte Senatorio oggi detto Ponte rotto. En Piranesi: "Opere varie dei Architettura prospettive grotteschi antichita sul gusto degli Antichi Romani". Inventate, ed. Incise da Gio. Batista Piranesi, Architetto veneziano. In Roma, MDCCL. B.A.S.F.: A-1077.

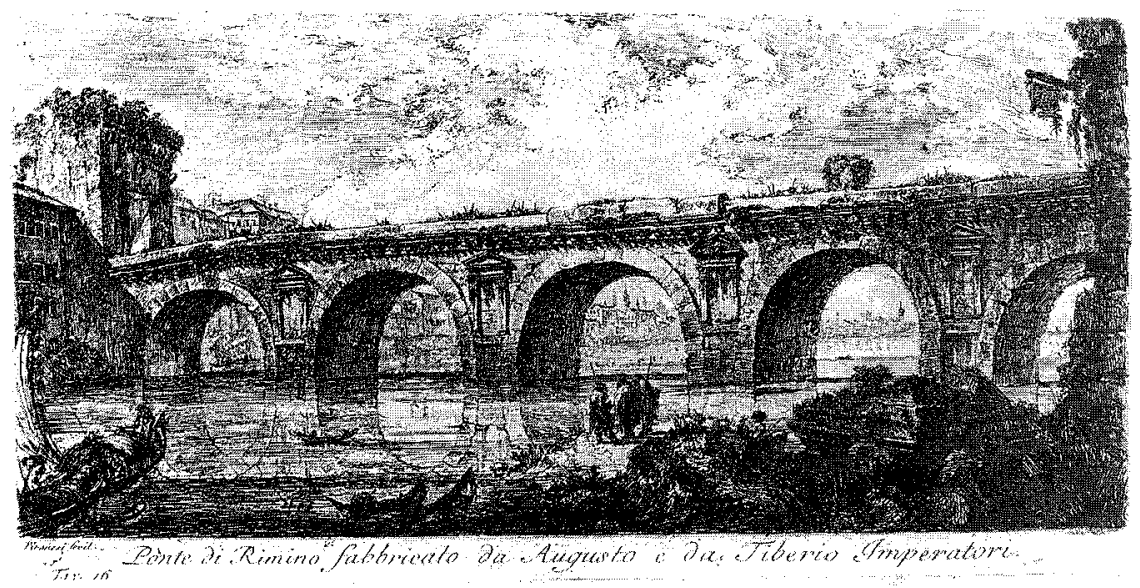

Fig. 4. Ponte di Rimino, fabbricato da Augusto e da Tiberio Imperatori. En Piranesi: "Opere varie dei Architettura...". In Roma, 1750. 
chos aspectos a Alberti, inició su estudio de los puentes proporcionando una serie de observaciones necesarias para su construcción y sobre el lugar, en el cual se debía asentar. Dio un tratamiento diferente a los de madera que a los de piedra, estableciendo una serie de modelos para aquellos, como el de César sobre el Rhin, de Cismone y de Bassane, y otra para estos últimos, cuales eran los de Vicenza y el de Rimini. Su aportación más novedosa es la propuesta de puente monumental de piedra de su invención bastante fantástico y hasta irrealizable al superponerle toda una arquitectura clasicista dentro de un repertorio formal especialmente manierista. El proyecto de puente estaba destinado a ubicarse en medio de una gran ciudad italiana junto al lugar de reunión de los mercaderes para tratar de sus negocios. Su idea era que contuviera tres calles, siendo la central más ancha que las laterales con una serie de tiendas y logias a semejanza del puente de Elio en Roma.

En la respuesta de la junta particular del 5 de diciembre de 1784 no se aludía para nada al tratado de Palladio y a su forma de construir los puentes, quizá porque su propuesta personal parecía ser poco operativa. Pero tampoco se hizo referencia a "Los Diez Libros de Arquitectura" de León Baptista Alberti, obra de la que la Academia poseía en su biblioteca varias ediciones, como la florentina de Cosimo Bertoli de 1550, o la publicada en Monte Regale por Lionardo Torrentino en 1565, o la española traducida por Francisco Lozano del año 1582, o la más cercana en el tiempo la romana de Giovanni Zempel de ese mismo año de 1784. Resulta extraño, así pues, que entonces no se citase este tratado como uno de los más adecuados para trazar los puentes.

Alberti, obsesionado por la conjunción entre la técnica y el estudio de sus proporciones, presentó al puente como la parte principal del camino, distinguiendo por su material de construcción entre los de madera, que consideraba más fáciles de realizar, y los de piedra, más laboriosos de hacer. En estos distinguía tres partes diferentes: los lados de las riberas o muros de contención o estribos, los pilares, las bóvedas o arcada, y la soladura o calzada.

Se mostró en primer lugar preocupado por la elección del sitio más conveniente para erigirlo, pues no todos los lugares reunían las condiciones necesarias. Subordinaba su existencia a estar al servicio, no del disfrute de unos pocos, sino para la comodidad de todos, motivo por el cual era conveniente ponerlo en medio de la región. Debía ser emplazado en un sitio adecuado por su facilidad y porque no ocasionase gastos excesivos, siendo duradero. De aquí la oportunidad de buscar vados poco profundos y estables, huyéndose de las orillas cortadas, de los lugares inciertos, de los remolinos y tragaderas del agua. Era preciso también huir 

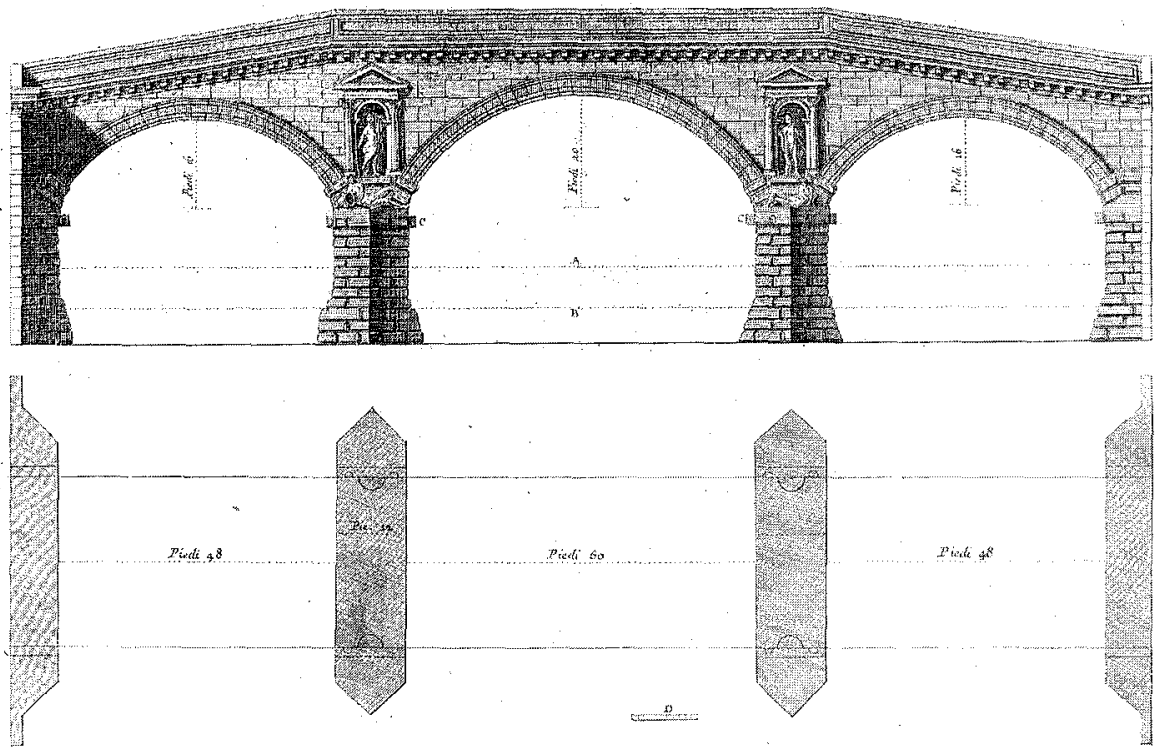

Fig. 5. Puente de Vicenza. En Palladio, Andrea: «Architettura». Quarta parte del Piede Vicentino col quali sono state misurate le seguenti Fabbriche. Venezia, Angiolo Pasinelli, 1740. Giorgio Fossati Architetto, inci. Vol. IV. B.A.S.F.: B-2839.

de los recodos de los ríos, pues sus riberas se hallaban sujetas a cambios continuos y eran objeto de aluviones.

El número de pilares, realizados con piedras muy grandes y resistentes por su naturaleza a los hielos y al agua, debía estar siempre en función de la anchura del río, situándose en los sitios por donde las aguas discurriesen más mansas. Se construirían sus cimientos durante el otoño, cuando hubiera menos agua, después de realizarse un dique de contención con dos filas de palos muy separados, cuyo interior sería rellenado con algas y barro, y con sus extremos sobresaliendo de las aguas, a los que se aplicaban por dentro cañizo. El espesor de los pilares debía ser la cuarta parte de la altura del puente.

Recomendaba que los arcos fueran nones, porque de esta forma se deleitaba más a la vista y también debido a que así se proporcionaba más solidad al puente. La parte central del cauce central del río discurre sin obstáculos y con más rapidez y fuerza al estar más lejos de la represión ejercida por las riberas.

Sin embargo, en la Academia madrileña se conocían a finales del siglo XVIII otros libros importantes de la época sobre la construcción de puentes, 
cuyos contenidos debieron incidir de algún modo en el diseño y censura en la Comisión de Arquitectura de este tipo de obras ingenieriles. Así, en el «Índice de los libros que existen en la biblioteca de la Real Academia de San Fernando", cuyo inventario fue realizado por Pascual y Colomer, su primer bibliotecario, hacia los años 1794 o 1795 se halla un libro de JeanRodolphe Perronet titulado "Description des projects et de la construction des ponts», publicado en París por la Imprenta Real en $1782{ }^{17}$. Esta obra fue reeditada ya en 1788, siendo aumentada con la descripción de los puentes de Château-Thierri, de Brunoi y el proyectado para San Petersburgo ${ }^{18}$.

La existencia de la primera edición de tal libro sobre puentes construidos en Francia durante la llustración en la recién abierta biblioteca de la Academia en una fecha tan cercana a su aparición certifica con elocuencia la influencia francesa en la construcción de este tipo de obras ingenieriles. El organismo madrileño no estaba anclado tan sólo en la posesión de los tratados del clasicismo, pues se adquirían libros modernos, abriéndose de esta forma tanto a la arquitectura francesa más avanzada con base en la física y en las matemáticas como a su ingeniería más novedosa. Pero, además, su posesión parece indicar que la Academia conocía la labor de la École des Ponts et Chaussés en Francia y de su director Perronet, que servían de modelos.

Perronet (Suresnes, 1708-París, 1794) fue un maestro indiscutible en la construcción de puentes. A él se deben, entre otros muchos, el de piedra de Nevilly sobre el Sena (1768-1774), el Pont-Saintre-Maxence (17741785) y el La Concorde en París (1786-1791), que son sus obras más celebradas. Fue primer ingeniero del Rey y director de la École des Ponts et Chaussés durante cuarenta y siete años. Ya en 1747 recibió la misión de formar a los futuros ingenieros, de construir y de dirigir obras públicas francesas ${ }^{19}$.

17 El inventario de Pascual y Colomer en A.A.S.F.: 71/3.

18 PeRronet, (Jean-Rodolphe): «Description des projets et de la construction des ponts de Neuilli, de Nantes, D'Orléans, de Louis XVI, etc... On y a ajouté le projet du canal de Bourgogne, pour la communication des deux mers par Dijon; et de celui de la conduite des eaux de l'Yvette et de la Bievre à Paris, en soixante et treize planches; approuvée par l'Académie Royale des Sciences. Dédiée au Roi. Par M. ...Nouvelle edition, Augmentée des ponts de Château-Thierri, de Brunoi, de celui projeté pour S. Pétersbourg, etc. d'un Mèmoire sur les cintres, et d'un autre sur les éboulements des terres, etc. Pour servir de complément à la nouvelle Architecture Hydraulique. A Paris, de l'Impremierie de François-Ambroise Didot, 1788.

19 Sobre Perronet véase el estudio de Michel Yvon, conservador de la Biblioteca de la École nationale des Ponts et Chaussées, a la edición facsímil de su libro: «Construire des ponts au XVIIe siècle». L'oeuvre de J.R. PerRonet. París, Presses de l'École nationale des Ponts et chaussées, 1987. 
Para poder acceder a la Escuela los aspirantes debían reunir una serie de condiciones indispensables. Debían ser solteros, disfrutar de salud, de buena conducta, tener excelentes conocimientos de geometria y dibujo, y ser presentados por alguna personalidad. En la École cursaban estudios de matemáticas, álgebra, secciones cónicas, mecánica, hidráulica, estereotomía, cálculo integral y diferencial. Empleaban como manual el «Cours d'Architecture" de Blondel.

\section{LOS PUENTES CENSURADOS EN LA COMISIÓN DE ARQUITECTURA}

La censura de los trazados de caminos y de la construcción de puentes dio mucho trabajo a la Comisión de Arquitectura de la Academia. Basta tan sólo referirse, cuantificando aquí, a que de los catorce expedientes vistos en las dos primeras juntas del 21 de abril y 4 de mayo de 1786 correspondían exactamente la mitad a esta tipología. Sin embargo, a finales del siglo descendió el número de proyectos de puentes censurados. Así lo demuestra el resumen de los asuntos de obras públicas de toda clase examinados por la Comisión de Arquitectura desde el 31 de agosto de 1796 hasta el fin de junio de 1799, elaborado por Silvestre Pérez entonces su secretario $-y$, por lo tanto, vicesecretario de la Academia- el 6 de julio de este año. De los 338 planos entonces vistos 27 correspondían a puentes en 6 expedientes y tan sólo 4 diseños a caminos.

Algunas veces la llegada de los planos de algún puente, o su realización material, originó que otro arquitecto, distinto del proyectista o del constructor, presentara quejas y hasta nuevo diseño para corregir los defectos, que en su opinión existian en el que se realizaría o se estaba ya edificando. En el fondo había un problema de competencias profesionales. Tales denuncias complicaban las resoluciones de la Comisión de Arquitectura y el trabajo de su vicesecretario, pues, por lo general, no se podía disponer a la vez de los expedientes completos o de todos los dibujos necesarios para juzgar con verdadero conocimiento de causa. En estos casos la burocracia crecía y se complicaba con la expedición de numerosos oficios. De ello resultaba que los asuntos tuviesen que tratarse insistentemente, una y otra vez, en diversas juntas hasta contradecirse a veces de alguna forma con relación a los dictámenes ya dados o tener que corregirlos sobre la marcha.

Este es el caso, como ejemplo significativo, de las quejas presentadas por Manuel Bernardo Mateo. El 5 de mayo de 1786 el Protector envió a la Academia un expediente, abierto con motivo de las mejoras y reparos sobre la disposición, calidad de materiales y firmeza que este Profesor de 
Arquitectura había propuesto en la fábrica de un puente sobre el río Guadalquivir, junto a la Venta de Alcolea, en el término de la ciudad de Córdoba. Los facultativos Juan Bautista Nebrony, director de la estructura, y Manuel Salgado, comisionado para la realización de aquel camino, salieron en defensa de la idea original y de la construcción de aquella obra.

Dicho expediente fue estudiado detenidamente en la Junta de la Comisión de Arquitectura del 19 de mayo. Los Profesores de esta disciplina en la Academia asumieron una posición ecléctica ante este debate, pues, si bien consideraban oportunos los reparos de Mateo, también tenían por convincentes algunas de las satisfacciones de Nebrony y de Salgado. La Comisión acordó responder al Protector pidiéndole que los arquitectos enviaran unos planos exactos del puente según se intentaba construir, y otro dibujo con plano y alzado de las cepas antiguas, que se iban a aprovechar con agregación de las 150 o 200 varas de terreno inmediato al desembarco del puente. Ello se debía a que no se había acompañado ningún dibujo con el expediente remitido. Pero la junta también propuso que Mateo enviara las trazas necesarias en su opinión para corregir los principales defectos advertidos por él en la construcción actual. Con tales proyectos la Comisión podría informar con pleno conocimiento de causa ${ }^{20}$.

En la junta del 28 de julio se volvió a estudiar el expediente del puente de las ventas de Alcolea, pues el dia 18 de ese mes el Protector habia enviado algunos de los dibujos pedidos: el de la fábrica antigua, del pensamiento de la nueva y del terreno inmediato. Examinados con atención y teniendo además presentes muestras de las piedras que se iban a usar en la construcción, aprobó la disposición del puente, su firmeza y el jaspe nuevo. Sin embargo, se acordó que se debían quitar la faja circular sobre las dovelas de los arcos exteriores y las banquetas de los dos lados del puente, para que se dejara un espacio más libre para el tránsito. Además, se dispuso que los tajamares de las cepas dentro de la madre del río se hicieran en ángulo rectilineo y que se observaran las «reglas del Arte, y el mayor cuidado para unir la fábrica nueva con la vieja, para elección de los materiales, economía, etc. ${ }^{21}$ ”

Pero el plano para enmienda de los defectos en la disposición y fábrica de este puente realizado por Manuel Bernardo Mateo llegó después. El

20 Actas de la Junta del 19 de mayo de 1786 de la Comisión de Arquitectura. A.A.S.F.: 3/139, fol. 35-rev. 36 anv.

21 Actas de la Junta de la Comisión de Arquitectura del 28 de julio de 1786. A.A.S.F.: 3/139, fol. 38 anv. y rev. 
Protector parecía estar muy interesado en esta obra pública, pues quería que en vista de todo este expediente, ya completo, la Academia expusiese si tenía que extender o reformar sus informes anteriores. La Junta advirtió que el proyecto de Mateo iba mucho más allá de una simple reforma de los defectos advertidos: en realidad, se trataba de fabricar otro puente nuevo. Consideraba que no era necesario ni fundarle en el sitio del viejo, como intentaba, pues tal vez fuera posible hallar otros lugares más ventajosos. Tampoco creía preciso demoler las cepas antiguas con sus consiguientes gastos.

Los arquitectos de la Academia debieron darse cuenta del gran interés que el nuevo proyecto de Mateo suscitaba en el ánimo del Protector y obraron en consecuencia de una forma diplomática, sin temor a contradecirse de alguna forma con su dictamen anterior. Manifestaron sus recelos sobre la buena trabazón de la obra vieja con la nueva del puente actual, coincidiendo, así, con las dificultades puestas por Mateo. No obstante, aconsejaron al Protector que nombrara a un arquitecto de su entera confianza para que reconociese el estado de la fábrica vieja y el método seguido en la construcción de la nueva, para que buscara y señalara los sitios más convenientes, si se necesitase hacer un puente nuevo, y que, por último, informara imparcialmente ${ }^{22}$.

Algunas veces los diseños realizados para hacer los caminos era censurado al mismo tiempo que los planos concebidos para la construcción o reedificación de los puentes necesarios en su trazado. En ocasiones tales proyectos no proporcionaban una idea exacta de la propuesta. Además, su coste era lo suficientemente elevado para que antes de aprobarse fueran vistos con cierta minuciosidad e informados por un arquitecto de la total confianza de la Academia.

Este es el caso, por ejemplo, de los dibujos y condiciones de Julián Sánchez, veedor de alarifes, presentados por la Contaduría General de Propios a la Academia, para realizar cuatro caminos, que salían de la villa de Lietor en el Reino de Murcia en dirección a Madrid, Andalucía, Murcia y Caravaca. La Comisión en su junta del 24 de octubre de 1786 dictaminó que era conveniente que el lugar y los proyectos fueran reconocidos con más exactitud e informados por uno de los dos arquitectos que proponía: por Bartolomé Ribelles, domiciliado en Valencia, o por Alfonso Regalado, quien tenía encomendada hacer otra comisión en aquel Reino. Se pensa-

22 Actas de la Junta de la Comisión de Arquitectura del 10 de agosto de 1786. A.A.S.F.: $3 / 139$, fol. 40 anv. 
ba que los caminos en los planos no seguian la línea recta y que los perfiles mostraban el terreno actual, pero no la forma con que quedarían después. Los profesores de Arquitectura consideraron que el puente de arriba podía situarse mejor y que el de abajo era imposible reedificarlo con el dinero presupuestado ${ }^{23}$.

En ocasiones llegaban a la Comisión diseños de varios puentes de una misma provincia para que se juzgaran de nuevo, después de haber sido vistos años antes por Marcos de Vierna. Así ocurrió con la reparación de diversos puentes y caminos en los términos de la villa de Valdeastillas, Boecillo y otros pueblos de la provincia de Valladolid, cuyas obras habían sido dispuestas por el profesor Francisco Javier de la Rodera y aprobadas por el Comisario de Guerra ${ }^{24}$. El expediente se había detenido en el año 1779. En la junta del 16 de agosto de 1787 Escolano, Escribano del Gobierno, lo remitió a la Academia a fin de que nombrara a un arquitecto académico para que reconociera de nuevo las obras, distinguiendo cada una de ellas y dando condiciones para su ejecución. La Comisión nombró a Alfonso Regalado Rodríguez ${ }^{25}$. Pero en marzo de 1788 la villa de Laguna envió un recurso a ese Escribano para unirlo al expediente existente. Se indicaban en dicha exposición las ruinas nuevamente acaecidas aquel invierno con las crecidas de aguas en el puente de Boecillo. La Academia volvió a encargar el reconocimiento a Regalado ${ }^{26}$, quien el 2 de mayo presentó una declaración. Incluía en ella las condiciones y los avances de tales obras, así como cinco dibujos de proyectos para los puentes nuevos de Valdeastillas y Boecillo, los reparos de los del Puente Duero y Villanueva de Duero, las calzadas y alcantarillas de Arroyo Ojuelos, Mermejuelas, Laguna y Boecillo, con el desagüe de la Salina de Laguna. La junta de la Comisión consideró excesivo la regulación del coste total de las obras, pidiendo que se repasasen con antelación los avances. Además Regalado no presentó en borrador el proyecto del puente de Boecillo, pareciendo los pilares delgados y endebles para su mucha altura, aunque fueran bastante gruesos para el vano de los $\operatorname{arcos}^{27}$.

23 Actas de la Junta de la Comisión de Arquitectura del 24 de octubre de 1786. A.A.S.F.: $3 / 139$, fol. 44 anv.

24 Un libro espléndido para el estudio de los puentes en Castilla y León entre 1575 y 1650 con algunas referencias al siglo XVIII es: ArambUru-ZabaLA Higuera, Miguel A.: La arquitectura de puentes en Castilla y León. 1575-1650. Valladolid, Consejería de Cultura y Turismo, Junta de Castilla y León, 1992.

25 A.A.S.F. 139/3, fol. 66 rev. Actas de la junta de 16 de agosto de 1787 de la Comisión de Arquitectura.

${ }_{26}$ A.A.S.F. $139 / 3$, fol. 85 anv. y rev. Actas de la junta de la Comisión de Arquitectura del 27 de marzo de 1788.

27 A.A.S.F.: 139/3, fol. 88 anv. y rev. Actas de la junta de la Comisión de Arquitectura del 8 de mayo de 1788. 
Los motivos económicos ocasionaron muchos de los dictámenes de la Comisión de Arquitectura, que en ocasiones tenía que encargar el diseño o esbozo de nuevos proyectos de puentes a algunos de sus profesores académicos para abaratar los altos costos de las obras. Así ocurrió, por ejemplo, con los dibujos realizados por Juan de Sagarvinaga a fin de construir un puente en la ciudad de Coria (Cáceres), cuyo avance económico excedía considerablemente, casi cuadriplicándolo, el presupuesto dado antes por Félix de Sota y Zubiría, cuyo plan se había rechazado en 1786 por cometer varias equivocaciones. La junta de la Comisión de Arquitectura del 27 de marzo de 1788 decidió para economizar suprimir el zampeado general y algunos ojos en el proyecto de Sagarvinaga. En este sentido Manuel Machuca fue encargado de realizar un apuntamiento con tales correcciones con la idea de que se enviase confidencialmente a aquel arquitecto a fin de que con arreglo a él satisficiera al Consejo ${ }^{28}$.

Sin embargo, algunas veces por razones de firmeza las juntas de la Comisión de Arquitectura preferían los presupuestos más caros a otros más baratos. Así ocurrió con las condiciones planteadas en dos proyectos del maestro de obras Lesmes Gabilán para la construcción de un puente, tres pontocillos y alcantarillas, y un trozo de calzada en la Arquería de los Huelmos, término del Jugar de Calzada de Valdunciel en tierra de Salamanca. En esta ocasión se aprobó el avance de obras más cuantioso por resultar de él una total firmeza y permanencia de la obra. No obstante, se le advirtió sobre la unión de las primeras dovelas de los arcos con las hiladas de los tajamares ${ }^{29}$.

Tal y como también ocurriera en otras obras públicas, los proyectos rechazados de algunos puentes fueron encomendados después a algunos de los profesores integrantes de las juntas de la Comisión. Pedro Arnal se comprometió, así, a reconocer en su viaje a la Mancha el sitio en el que se deseaba construir un puente en el río llamado de la Vega, contiguo al lugar de Tirate Afuera ${ }^{30}$. También se le encargó en noviembre de 1787 realizar un proyecto más arreglado para la construcción de un puente en Navalcarnero, después de que unánimemente se hubieran rechazado por inservibles - «destituidas del verdadero conocimiento facultativo»los planos y las condiciones elaborados por Manuel Serrano debido a que

28 Actas de la Junta de la Comisión de Arquitectura del 27 de marzo de 1788 . A.A.S.F.: 139/3, fol. 85 rev.

29 Ibidem, A.A.S.F.: 139/3, fol. 80 anv.

so Ibidem, A.A.S.F.: $139 / 3$, fol. 85 anv. 
podrían resultar perjuicios en la obra y pleitos con los asentistas ${ }^{31}$. En este mismo sentido el teniente director Manuel Machuca fue encomendado para reconocer la reparación del puente de la Cartuja en el término de Jerez de la Frontera en su viaje a Cádiz de $1787{ }^{32}$.

La Academia encargó nuevos diseños de la mayoría de los proyectos de puentes reprobados por la Comisión, así como las visitas y los reconocimientos a los lugares donde se iban a construir, a profesores académicos de su plena confianza, la mayoría de ellos formados en sus aulas, según la proximidad a su lugar habitual de residencia o aprovechando uno de sus viajes a lugares próximos. En este caso cobraban dietas tan sólo desde el lugar en el que se hallaban. De esta forma, Alfonso Regalado Rodríguez, Diego de Ochoa y Francisco Álvarez de Benavides se ocuparon de las obras a realizar en la provincia de Valladolid o de otras cercanas a ella. Ochoa junto con Alexo de Aranguren hizo varios dibujos para la reparación del puente principal de Logroño en $1786^{33}$. Se encomendó a Fernando González de Lara las de Burgos. Juan de Sagarvinaga se hizo cargo de los proyectos de puentes de Salamanca y Cáceres. También trabajo en la villa de Rueda, cerca de Medina del Campo (Valladolid), en 1786. Se encargó a Miguel Ferro Caaveyro de los gallegos. Domingo Tomás, director de la Escuela de Dibujo de Granada desde finales de $1786^{34}$, estuvo ocupado con la realización de obras públicas de esta región y en Málaga, aunque en ocasiones se encargaran proyectos en Andalucía a Francisco Quintillán y Lois, quien también vivía en Granada. Agustín Sanz, formado en la Academia madrileña en la década de los años sesenta, trabajó en Aragón, reparando entre otras muchas obras el puente de piedra de Zaragoza en 1787, cuya compostura forzosa del último arco por él propuesta fue aprobada por la Comisión, que recomendó realizar una especie de malecón con dos líneas de piquetes en la parte baja de dicho puente para prevenir daños sucesivos ${ }^{35}$. Olagivel realizaría

31 Juntas de la Comisión de Arquitectura del 16 de mayo y 16 de noviembre de 1787. A.A.S.F.: 139/3, fol. 59 anv.-rev., y fol. 75 rev. y 76 anv.

${ }_{32}$ Actas de las juntas de la Comisión de Arquitectura del 30 de agosto y 11 de octubre de 1787. A.A.S.F.: 139/3, fols. 67 rev. y 72 rev.

33 Actas de la junta de la Comisión de Arquitectura del 7 de septiembre de 1786. A.A.S.F.: 139/3, fol. 41 rev.-42 anv. La Academia ya había informado sobre estos dibujos el 4 de noviembre de 1785. Ahora solicitaba informe circunstanciado sobre los planos y condiciones que para la misma obra habian dado Diego de Ochoa y Alexo de Aranguren.

34 García Melero, José Enrique: «Retazos de la Escuela de Dibujo de Granada en la Real Academia de Bellas Artes de San Fernando (1777-1816)". En "La imagen romántica del legado Andalusi", pp. 125-138. Granada, 1995.

${ }_{35}$ Junta de la Comisión de Arquitectura del 8 de febrero de 1787. A.A.S.F.: 139/3, fol. 51 anv. y rev. 
obras en Vitoria, su lugar de residencia, y en sus proximidades. Bartolomé Ribelles era recomendado por la Academia para trabajar en Valencia y Murcia... ${ }^{36}$.

La Academia propuso de modo alternativo algunas veces a dos profesores para reconocer puentes y formar planos de ellos, que vivían o se hallaban próximos al lugar, a fin de que el Consejo o el Escribano de Gobierno eligiera uno de ellos. De este modo ocurrió, por ejemplo, en la reunión de la Comisión de Arquitectura del 26 de julio de 1787. Entonces se trataba de realizar el reconocimiento y hacer plano para el puente de Garciez sobre el arroyo Salado. Se pedía el nombramiento de un profesor de las inmediaciones de la ciudad de Jaén. Como se tenía la noticia de que el profesor Francisco Antonio Quintillán y Lois se hallaba en Santa Fe de Granada se le propuso en primer lugar, y en su defecto al académico Domingo de Tomás, que residía en Granada ${ }^{37}$.

Parece necesario indicar aquí que, si bien durante este período se construyeron numerosos puentes de nueva planta a lo largo de los caminos ya existentes o de los que entonces se abrían, también se repararon otros muchos. Esta tipología en especial pragmática no es, obviamente, estática, sino casi siempre bastante dinámica al ser objeto a menudo de modificaciones debido a su desgaste continuo por el lógico efecto del paso del tiempo y de los fenómenos atmosféricos devastadores, causantes de riadas y de grandes avenidas de aguas destructoras de sus estructuras. Así, estos cambios, más de consolidación, de firmeza, que formales, suelen ser mucho más frecuentes en los puentes, donde se amalgaman diferentes estilos artísticos, que en otros tipos de construcciones. De esta forma, las reparaciones de los ya existentes desde diferentes épocas, más - menos remotas y cercanas a la época de la llustración, y que habían sufrido cambios en otros períodos fueron muy numerosas en la labor censoria de la Comisión de Arquitectura.

Los arquitectos académicos dieron juicios de valor muy diferentes en estas juntas de la Comisión sobre los proyectos de puentes que llegaban a la Academia. Pero el fundamento de tales censuras se halla en dos aspectos importantes: solidez, sí, pero también economía, aún sin prescin-

\footnotetext{
36 Información sobre puentes proyectados por los discípulos de Ventura Rodriguez en: SAMBRicio, Carlos: "Datos sobre los discipulos y seguidores de D. Ventura Rodríguez". En "Ventura Rodriguez (1717-1785)", pp. 245-304. Madrid, Real Academia de Bellas Artes de San Fernando, 1985.

${ }^{37}$ Junta de la Comisión de Arquitectura del 26 de julio de 1787. A.A.S.F.: 139/3, fol. 64 anv. y rev.
} 
dirse plenamente de la buena disposición y regularidad; mas ahora sobre todo se exige firmeza. La estricta normativa formal clasicista parece estar en los puentes algo más distante que en otras tipologías arquitectónicas. El elemento práctico se superpone a otros más estéticos en estas obras, auténtico campo de batalla entre arquitectos e ingenieros en épocas siguientes, pero próximas en el tiempo, y aún en mentalidad, a la llustración. De ahí el interés que el presupuesto de cada puente despertó en la Comisión. Era preciso compaginar la «bondad» de la obra con su «menor coste». Las advertencias de los arquitectos de la Academia giraban casi siempre en torno a la "mayor economía" y a la "perfección" del puente.

La Academia exigía que los arquitectos enviasen en el proyecto, no un diseño en perspectiva, sino geométrico con planta y alzado del puente, así como un perfil a lo largo, que manifestara el desnivel del terreno ${ }^{38}$. Pero también se pedía un informe facultativo, o estudio o declaración, en el cual se incluían las condiciones y los avances de las obras. Obviamente era fundamental proponer su coste total, que siempre se hacía constar en las actas de las juntas de la Comisión de Arquitectura. El plano, o los planos, junto al informe, o informes, del proyectista eran remitidos por la Escribanía de Gobierno, constituyendo su conjunto un expediente, al Secretario de la Academia. Este a su vez lo pasaba al Vicesecretario, que era el Secretario de la Comisión, por medio de un oficio con la relación minuciosa o minuta de los expedientes incluidos.

Los proyectos de puentes precisaban cierta actualización debido a las variaciones que podían sobrevenir en los terrenos y sitios elegidos para construirlos y, también, a causa de las oscilaciones en los precios de las obras. Su realización material muchas veces solía confiarse a los mismos proyectistas, que cobraban su labor a jornal. La Academia rechazaba los ajustes de obras. En ocasiones se les permitía, expresándose así en los informes censores y en las actas de las juntas de la Comisión, nombrar a un aparejador de su entera confianza y de asistencia continua para que supliera sus ausencias.

Cuando un determinado proyecto de puente no merecía ser reprobado plenamente, pero exigía ciertas correcciones, la Comisión solicitaba de uno de sus miembros un apuntamiento con las enmiendas a realizar, que muchas veces se enviaba de forma confidencial al proyectista. Pero también las rectificaciones se indicaban por escrito con todo detalle en los in-

38 Censuras de los puentes grande y nuevo de Dueñas. Junta de la Comisión de Arquitectura del 8 de mayo de 1788. A.A.S.F.: 139/3, fol. 87 anv. 
formes de censura, si no precisaban de un diseño más gravoso de realizar. Así, por ejemplo, la junta del 11 de octubre de 1787 dispuso que Mateo López hiciera - sin más remuneración que la recibida por los primeros dibujos - otros proyectos arreglados para un puente en la villa de Torquera en la provincia de Cuenca, debido a que había «tenido varios descuidos culpables". Se le recomendaba que considerase cinco aspectos diferentes en los nuevos diseños que había equivocado en los presentados: hacer otro arco por lo menos en el lienzo de las vanguardias para desahogo de las avenidas; que el zampeado y encadenado sólo fuese debajo de las cepas; que el ancho del puente fuera proporcionado para dos carruajes por lo menos respecto de ser estrecho con los 14 pies que había dado; que los tajamares subieran hasta el tercio de los arcos, y que los antepechos no fueran de hilada, sino de una pieza ${ }^{39}$.

Era muy frecuente que se necesitara realizar un reconocimiento - previo a la formación de planos, valuación y condiciones- del estado de un cierto puente o del sitio donde se construiría de nueva planta. Para ello se nombraba un arquitecto de confianza de la Academia, quien podia regular las obras, suprimiendo algunas o adicionando otras. Se solían encargar, además de a los profesores arquitectos residentes en las distintas provincias, a uno de los académicos de mérito integrantes temporalmente, de forma alternativa cada dos años, de la Comisión de Arquitectura. Hacían auténticos itinerarios por determinadas regiones, revisando diversas obras y gozando de numerosos encargos retribuidos a base de dietas.

El precio de la obra estaba en función de las dimensiones del puente, de los accidentes del terreno, de los materiales a emplear — prefiriéndose en este período la piedra a la madera - y del número de arcos que tendría. Se elegía, obviamente con la finalidad de facilitar la construcción y abaratar los presupuestos, para levantarlo un pasaje, donde el río tuviese los márgenes más estrechos y el curso de agua pudiera ser perpendicular al puente. En las reconstrucciones se aprovechaban, por lo general, todas las partes aún servibles, que eran consolidadas. De aquí que muchos puentes sean auténticos rompecabezas de amalgamas de diversas épocas y estilos, y muy difíciles de delimitar cronológicamente con total precisión.

Los motivos de reprobación de los proyectos por parte de la Comisión de Arquitectura fueron bastante diversos. La falta de una buena disposición, regularidad y firmeza junto con presupuestos desajustados o excesi-

39 Actas de la junta de Comisión de Arquitectura del 11 de octubre de 1787. A.A.S.F.: 139/3, fol. $71 \mathrm{rev}$. 
vos, como antes se ha dicho, solian ser las causas principales para rechazarlos. Pero también lo era el desconocimiento total por parte de sus miembros de la calidad y titulación del proyectista. Se pueden enumerar aquí entre otros móviles, explícitos elocuentemente en las actas, los siguientes: la mala disposición de las cimbras, dudas sobre la elección del sitio donde se iba a levantar, carga excesiva de los tajamares o no hacerlos en ángulo rectilíneo, empleo de malos materiales, diferentes tasaciones, cuesta de entrada al puente demasiado pendiente, poca altura o grosor de los arcos... 
